\title{
El Universo Íntimo de Marina Mayoral: Brétema
}

\author{
Anna Corts Curto* \\ Universitat Rovira i Virgili, Tarragona, Spain
}

\begin{abstract}
Painting scenarios where to place characters with their stories is one of the most complex tasks in characterizing the space of a literary work. Most authors change space each time they start a new novel. In the case of Marina Mayoral, we found a room of her own, a closed universe that has its well-defined contours. In Mayoral, the central space of each work is directly related to a term: Brétema. In this paper, we will try to draw contours in an amazing world that takes its name in La única libertad (Mayoral 1982) and that links all her works.
\end{abstract}

Keywords: Brétema, Marina Mayoral, Deseos, setting.

Resumen. Pintar escenarios donde situar unos personajes con sus historias es una de las tareas más complejas en la caracterización del espacio de una obra literaria. La mayoría de los autores cambian de espacio cada vez que empiezan una nueva novela. En el caso de Marina Mayoral, encontramos un cuarto propio, un universo cerrado que tiene sus contornos bien definidos. En Mayoral, el espacio central de cada obra está directamente relacionado con un término: Brétema. En este trabajo, intentaremos trazar contornos en un mundo sorprendente al que se da nombre en La única libertad (Mayoral 1982) y que va enlazando todas sus obras.

\footnotetext{
* Author's address:

Departament de Filologies Romàniques

Universitat Rovira i Virgili

Av. Catalunya 35, 43002 Tarragona, Spain

E-mail anna.corts@estudiants.urv.cat
} 
Palabras clave: Brétema, Marina Mayoral, Deseos, escenario.

\section{Creando Espacios}

Para os galegos, a brétema é un pano fino de fantasía que nos leva máis alá do entendemento. Un estado de ser que nos permite adentrarnos sen medo nas profundidades do pensamento.

Pintar escenarios donde situar unos personajes con sus historias es una de las tareas más complejas en la caracterización del espacio de una obra literaria. Por ello, autores de novelas, obras de teatro relatos ponen especial atención en una determinada ciudad, una callejuela, una playa o simplemente una habitación. El marco que sostiene el lienzo de aventuras de amor, de desamor, de venganza o de misterio es el que acompaña a cada personaje desde el comienzo al final de su propia historia.

Los creadores irán en busca de un espacio que les permita el desarrollo de todo lo que está dibujado, o más bien esquematizado, en su memoria. Se trata de encontrar el lugar exacto donde una historia puede convertirse en una realidad y donde cada personaje se siente cómodo para actuar de un determinado modo y desarrollar sus inquietudes. Pero encontrar el lugar oportuno para enmarcar toda una obra literaria no resulta sencillo; de aquí que la mayoría de los autores cambien de espacio cada vez que empiezan una nueva novela. Puede ser que, según la historia que se esté narrando, una ciudad como París sea la más adecuada; otras veces será mejor Madrid, y otras, un pueblo pequeño de montaña.

Lo que nos llama más la atención de este proceso de búsqueda profunda del espacio adecuado es el trabajo que lleva a cabo Marina Mayoral. Entramos en un cuarto propio, un universo cerrado que tiene sus contornos bien definidos. En Mayoral el espacio central de cada obra está directamente relacionado con un término: Brétema.

Brétema significará un territorio poco preciso, de contornos difuminados, envuelto en una niebla de la que surgirán poco a poco los personajes. Lo primero que veremos será este paisaje, en realidad, la niebla que oculta la poca luz y esa naturaleza exultantemente bella que espera que una nueva mirada la descubra. En las novelas de Mayoral esta habitación solo se hará visible a 
través de los ojos de los protagonistas que le van dando forma y revelan al lector, poco a poco, sus secretos y su belleza. En palabras de Mayoral:

Por eso no hay una visión objetiva de Brétema: cambia según quien la mira, o según el momento de esa mirada.

Con esta breve aproximación al universo de Marina Mayoral intentaremos trazar contornos en un mundo sorprendente al que se da nombre en La única libertad (Mayoral 1982) y que va enlazando todas sus obras.

\section{Amanece en Brétema}

El lector abre la página del libro y entra en un lugar imaginario que se corresponde con realidades del mundo de Marina Mayoral. Este espacio lo creó en los años ochenta y en él se desarrollarán la mayoría de sus novelas y algunos cuentos; en realidad se trata de eso, de un lugar ficticio, aunque con muchas características de su tan querido mundo gallego.

El reconocimiento de Brétema como un espacio narrativo propio de Mayoral es indiscutible. Serán veinte años de historias, secretos, misterios, felicidad y niebla. Todo cubierto por un velo de niebla.

A lo largo de numerosas entrevistas concedidas por Mayoral a medios como Cervantes TV o Periodista Digital, la definición de su universo íntimo ha sido la misma. El lector se sumerge en un marco imaginario que apareció como tal, con el nombre de Brétema, en La única libertad (Mayoral 1982). Anteriormente, su espacio narrativo estaba dividido en muchos otros: la ciudad de Santiago, Lugo, Mondoñedo, Foz, la costa norte, etc., fuentes de inspiración que la llevaron a la búsqueda de una sola ciudad, un lienzo en el que situar a sus personajes y sus historias. Ella misma lo definió con estas palabras:

Me di cuenta de que debía unificar esos rasgos de España y crear un espacio nuevo imaginario [...] y fue Brétema, y desde ahí la utilizo siempre.

Algunas veces Brétema aparecerá como lugar en que se sitúa toda la acción narrativa; otras será el lugar de procedencia de algunos personajes, el lugar de un recuerdo pasado, una vivencia inolvidable... Es habitual en su 
obra narrativa que sus personajes procedan de pueblos o pequeñas ciudades. Muchos de ellos emigran, la mayoría a Madrid, algunos hasta Nueva York, pero todos regresan, al menos con los recuerdos, a sus raíces, a su pequeña ciudad. Y así, poco a poco, con la lectura del largo número de páginas de sus obras, el lector va precisando este espacio que se nos describe con pocos rasgos en cada nueva aventura.

Brétema representará también la tensión entre la ciudad pequeña de provincias, donde todos se conocen, y la ciudad grande, como es Madrid:

Situar a mis personajes en Brétema es muy cómodo. La gente que vive en una gran ciudad busca la libertad, pero, por otro lado, anhela sentirse parte de algo.

Sus rasgos gallegos son innegables. Será un paisaje que influye en el carácter de los personajes; incluso tendrá el carácter íntimo, de desconfianza, que tienen los propios habitantes, lo que hace que la acción se vea envuelta de cierto aire de misterio.

Sin duda se trata de un espacio íntimo, cerrado y personal; sin embargo, hay que tener en cuenta que el otro elemento que influye en este universo nos lo aporta la terminología de la propia palabra: Brétema. ¿Qué significa? Si repasamos las definiciones que se dan del término en diferentes diccionarios, entre las distintas acepciones encontramos las siguientes:

Niebla, principalmente la espesa, baja y con ventisca (Reguera y Pardiñas 1840-1858).

Niebla. Voz gallega. En griego brecho o brejo v. significa humedecer, empapar, rociar, mojar: cosas que puede hacer la niebla. En árabe ...*hebreo ...* i. e. bred significa 'frigus' o 'frío'. Uno de los efectos que produce la niebla. Por consiguiente parece indudable que la voz gallega procede de la raíz oriental de las voces sobredichas (Anónimo 1845c).

Niebla, vapor á modo de nube rastrera. Se llama meona cuando es húmeda; maligna, cuando abrasa y quema las mieses y más plantas con su fruto (Rodríguez 1863). 
Niebla. Nube cargada demasiado de vapor acuoso, que se extiende sobre la superficie de la tierra por no poder subir a la región del aire. Cuando es húmeda y deja salpicadas de finísimas gotas de agua todas las cosas que toca, se llama brétema mexona, y si está cargada de otros vapores que quema y abrasa las mieses, se le da el nombre de maligna (Porto Rey 1900c).

Niebla. Bruma. Vapor acuoso y denso que se extiende sobre la superficie de la tierra por no poder subir a causa de su pesadez (Carré Alvarellos 1928-1931).

La BRÉTEMA recibe varios nombres, según las cualidades y condiciones con que se presenta. Llámase BARRUFA cuando es muy húmeda y sus gotas son casi imperceptibles; MALINA, cuando abrasa y quema las mieses y los frutos; MERA, cuando es fría y daña los plantíos, amerando sus frutos; MEXONA cuando es persistente y cae en menudas gotas que mojan; NÉBOA, cuando obscurece más o menos la atmósfera y anda tan baja que cubre de NEBOEIRO los campos sin mojarlos; y ORBALLENTA, cuando es tan lloviznosa y tan mansa que parece columpiarse en el aire a merced del tiempo (Rodríguez González 1958-1961).

En Brétema se difuminan los contornos de todo aquello que envuelve a los personajes y sus vidas. El hecho de esconderse siempre, de no ir nunca de frente, un rasgo característico de las gentes gallegas, se verá aumentado por la niebla presente en todo momento, día tras día, y que hace que el universo de Mayoral adquiera un tono único, con algo de blanco y algo de oscuro, pero siempre difuso, inmaterial.

La autora definió perfectamente la atmósfera que quería crear para que se movieran sus personajes y sus historias. En una de sus entrevistas pronunció lo siguiente:

En pequeñas localidades de Galicia todavía se corren los visillos para ocultar su intimidad como ocurre en la novela.

En Galicia hay esa cosa de esconderse siempre; también es la niebla, el no ir de frente. 
Es el hecho de no decir las cosas claras, siempre con temor al qué dirán, siempre dejando en suspenso la duda que puede dar un giro a una situación, a una historia, e incluso puede cambiar el rumbo de una vida.

Brétema sugiere, en palabras de la propia autora, el norte. Es el punto de orientación y adquiere carácter universal. Todo lo que sucede en este marco puede ocurrir en cualquier lugar del mundo. El murmureo, el escondite, el misterio, el mirar por detrás de las ventanas, el preguntarse por la vida de los demás, el imaginar y el soñar son aspectos que ocurren en todos los lugares del mundo, de modo que esta pequeña ciudad se convierte en un referente colectivo.

Por otra parte, el no mostrarse típico de los gallegos hace que cada personaje y cada conversación queden enmarcados en una niebla densa que solo logra levantarse algunas veces para dar cuenta a los ojos del lector de un hecho que será posiblemente sorprendente. Es en esos instantes cuando aparece la luz y el verde del bello paisaje gallego. Pero mientras eso no ocurre el murmureo y las sombras siguen flotando en esta atmósfera, que sin duda es única.

Mayoral despierta la magia de un espacio que parece casi ensoñado, con el sonido de las gotas de lluvia presente día tras día o con el color blanco que pinta cada ángulo. Es un lugar que te atrapa, del que no puedes dejar de preguntarte acerca de cada calle y cada ventana, la iglesia, la plaza, el cementerio... Todo allí esconde unos ojos curiosos que se preguntan cuál ha sido el motivo que ha llevado a sonar las campanas de un modo tan violento en un día aparentemente tan normal.

Blanca, uno de sus personajes, la describe de este modo en el último capítulo de Recóndita armonía:

En Brétema, casi todos los días al atardecer cae la niebla; baja despacio desde los montes y se desliza hasta rozar los tejados. Pocas veces llega hasta las calles $\mathrm{y}$, si lo hace, es en forma de velo muy tenue, casi imperceptible, que solo se nota porque deja una pátina de humedad sobre las piedras. Si se viene en coche por la carretera hay un momento en que se ve todo el valle sumergido bajo una masa algodonosa que lo oculta por completo. Arriba en la montaña brilla el sol y abajo en el valle hay una luz difusa que no hace sombras. A mí me gusta y para la piel es muy buena. La gente de Brétema se arruga menos que la de otros sitios. Porque además es muy húmedo; cuando no hay niebla, llueve. 
Brétema es también un lugar solitario. No quiero decir que no haya gente sino que se ve poca gente por la calle; puedes asomarte a la ventana y no ver a nadie durante largo rato. De vez en cuando pasa una niña corriendo, o un cura con sotana andando despaciosamente. A veces las campanas suenan a muerto durante todo el día. Por la noche en toda la ciudad se oyen los cuartos y las horas del reloj de la Catedral, y el toque de las clarisas a la una de la madrugada, y el de los frailes de la Merced a las seis y media (Mayoral 1994).

\section{Una Habitación Propia (otras obras)}

Brétema aparece por primera vez en La única libertad (Mayoral 1982), donde Mayoral crea ya un lugar imaginario que en la novela sustituye a Santiago de Compostela. Veremos que, a partir de este momento, en el paisaje de cada obra aparecerá Brétema, ya sea en forma de recuerdo, en un viaje de vuelta o como destino de alguien.

Sin embargo, en el primer capítulo de esta novela leemos lo siguiente: "La carta estaba fechada en Santiago hacía veinte días" (Mayoral 1982).

Vemos que, en el momento en que Mayoral decide crear un nuevo escenario, aparecen vacilaciones según las ediciones de las novelas. En la edición de 1992 de la editorial Castalia, Germán Gullón (1992) habla de Brétema en el prólogo y anuncia lo siguiente:

En Cándida otra vez el uso de los topónimos cambia de una edición a otra. En la primera edición se usan dos nombres diferentes: Santiago de Compostela y Viladomar. El final de la novela es abierto y el lector tiene que elegir entre las distintas posibilidades (Gullón 1992).

En un primer momento Mayoral pensó en un espacio narrativo donde se movieran sus personajes, en un espacio donde desarrollar las historias de todos ellos; ese lugar tenía que ser único y válido para todas sus obras posteriores, además de ser donde más cómoda se sintiese en su momento de creación. Después de la publicación de esta novela decidió cambiar los nombres de algunos topónimos usados en las dos primeras, para dar unidad a su obra en el sentido espacial. Veamos a continuación lo que apuntan algunas de las críticas referentes a Brétema: 
X.L. Franco Grande (2011), en Máis luz en Brétema, dice:

O condado de Yoknapatawpha, en Faulkner; a cidade de Santa María, en Onetti; Macondo en García Márquez, ou Brétema, en Marina Mayoral, quedarán como referencias míticas da literatura deses autores. Na última deles, o ser Brétema segue anovándose e expandíndose, como o acredita a súa última novela, por agora, baixo o título Deseos, recén publicada por Alfaguara. [...] Hai moito contido na nova novela de Marina, dende personaxes moi ben debuxados a técnicas narrativas moi eficaces, todo o cal compón unha sólida peza narrativa que arrequece a súa xa numerosa obra á par que enche de luz as brétemas da súa imaxinaria Brétema, anovándoa, expandíndoa, arrequentándoa, iluminándoa. Para gozo de todos nós, os seus lectores (Franco Grande 2011).

Por su parte, Ángel Basanta (2011) en su artículo Deseos nos dice:

Con más de veinte obras, entre novelas y libros de cuentos, escritas en más de treinta años, en castellano y en gallego, Marina Mayoral (Mondoñedo, 1942) ha ido construyendo una trayectoria narrativa que ha ganado en interés y calidad literaria. Esto se cumple también en Deseos, novela redonda que considero la mejor de las suyas. Porque además de conseguir una estructura narrativa caleidoscópica como artefacto privilegiado para novelar la vida de una pequeña ciudad de provincias, contribuye a ampliar y a anudar con nuevos vínculos el microcosmos literario de la autora, con explícita inclusión de personajes que habían aparecido ya en novelas anteriores. [...] Se completa una espléndida novela psicológica, rica en sensaciones y matices, en la que todo confluye en un canto al amor y a la escritura (Basanta 2011).

Tomando lo anterior como punto de partida, nos proponemos viajar a lo largo de las distintas novelas para comprobar cómo aparece Brétema, cómo se describe y qué lugar o papel desempeña para sus habitantes. El lector, libro tras libro, va descubriendo un poco más de este universo que atrapa y que hace soñar a más de uno con pisar sus calles y sentir sus murmureos.

Como hemos anunciado, en La única libertad, Mayoral (1982) da nombre al espacio que ha pensado como ideal para construir toda su obra narrativa. En realidad, tiene referencias de los espacios más importantes o que más 
significado tienen en su propia vida: Mondoñedo, su ciudad natal; Foz, con su costa dura del norte, donde veraneaba de niña; Lugo, donde pasó algunos años de su infancia; Santiago de Compostela, donde comenzó a estudiar la carrera, etc. De todos ellos ha sacado alguna característica para conformar su propia ciudad: Brétema. En esta novela aparece como el pueblo donde está situada la casa de las tías abuelas en que Etelvina intenta escribir la historia de La Braña.

Es habitual en su obra narrativa que sus personajes procedan de pueblos o pequeñas ciudades. Y, como ya hemos apuntado, esos personajes estarán muy vinculados emocionalmente con Brétema. Será a lo mejor un lugar de paso, un destino; significará un adiós, un hasta pronto o un lugar para el recuerdo.

Para Oscar Leonés (1982), en Una familia lejana:

Si escribir una buena novela consiste en crear un mundo, un mundo en orden suyo y nuevo es lo que ha puesto en pie Marina Mayoral en su última novela [...] (Leonés 1982).

La siguiente obra donde aparece Brétema es Recóndita armonía (Mayoral 1994). En cuanto al espacio narrativo, los personajes se mueven entre Brétema y Madrid, adonde se trasladan a estudiar y más tarde a trabajar. La acción centrada en Brétema será la que dé cuenta de las diferencias que separan a Blanca de Helena y las hace más patentes: Blanca adora estar allí y Helena se ahoga. Una vez en Madrid veremos cómo esas diferencias se diluyen.

En esta novela, Mayoral ofrece a sus lectores más datos sobre el espacio propio. Blanca plasma en el texto unas páginas muy hermosas en las que va contando pormenorizadamente cómo era su vida en esta pequeña ciudad, sus costumbres y rutinas. El lector, a partir de los datos que se le van ofreciendo, se siente poco a poco más inmerso en Brétema.

Según Salustiano Martín (1995):

Marina Mayoral domina el instrumento narrativo [...] La recurrente utilización del ámbito de Brétema, con la pertinente ubicación relacional de los personajes, le permite un juego referencial que sitúa los entresijos de la ficción como partes indiscutibles del mundo real (Martín 1995).

¿Quién mato a Inmaculada de Silva? (2009) es la siguiente obra narrativa enmarcada en un ambiente predominantemente rural y de pequeña ciudad. 
Corresponde a La Braña, la casa solariega de los Silva, donde sucedieron los hechos del pasado, y a Brétema, donde la protagonista pasa el verano. Veremos cómo algunos de los sucesos que cuenta Etelvina tienen lugar en Madrid y en Nueva York, donde ha vivido con Alberto, el hermano gemelo de su madre. Sin embargo, el espacio que aparece con más frecuencia y en el que se centra toda la obra es rural, y cobra gran relevancia porque allí ocurren la mayor parte de los episodios en que se vieron implicados los maquis durante la posguerra española.

Centrar la acción en Brétema le ofrece una vez más la paz que necesita para narrar hechos históricos, para volver la mirada al pasado y recordar, puesto que Brétema es el espacio ideal para dejar fluir la mente, para lanzarse a sentir entre la lluvia constante que invita a la reflexión y a la nostalgia.

Finalmente llegamos a Deseos (Mayoral 2011), su última novela, la que recurre a Brétema desde la primera a la última página. Más bien podríamos decir que se convierte aquí en un personaje más, que sirve de hilo de unión con los diferentes personajes y sus historias y vidas.

Veamos el argumento de la novela:

Amanece en Brétema. Desde algunas ventanas se ve a Héctor Monterroso andando calle abajo. Son las seis y media de la mañana, lo acaban de anunciar las campanas de la catedral. Desde ese momento, una violación, una muerte y un accidente trastocaran la vida de la pequeña ciudad, arrancándola de su aparente tranquilidad (Mayoral 2011).

Diversos críticos han expresado sus opiniones sobre Deseos. Para Suárez Lafuente (2011):

[...] Mayoral consigue concentrar en el microcosmos de Brétema, a lo largo de un día, las grandezas y miserias de una comunidad cualquiera (Suárez Lafuente 2011).

Su universo íntimo se va sucediendo obra tras obra y nos va descubriendo un mundo que, aunque pertenece a su imaginación, cada lector hace suyo; en diversas ocasiones incluso le puede parecer que lo está tocando, que está respirando su niebla y andando por sus calles. En otras obras también aparece mencionada Brétema, pero solo como lugar de referencia de la vida de algún personaje, de un momento vivido importante, el lugar de un nacimiento, etc. 
En Contra muerte y amor (Mayoral 1984) aparece Tolda, el barrio pobre de Brétema, que será el lugar de nacimiento de María Novoa. El reloj de la torre parece que intenta enmarcarse en Brétema, pero no encontramos el topónimo definido en ninguna de sus páginas. El espacio narrativo de La sombra del ángel es claramente Brétema. En los recuerdos de los protagonistas aparecen los veranos en el mar, y lo que sucedió en una cueva que recuerda la Cova do Mar de Cándida, otra vez (Mayoral 1992). Serán escenarios que van configurando el pequeño, aunque eterno, espacio de Brétema.

Gómez Yebra (2000) afirma que:

Marina Mayoral nos permite comprobar en 'La sombra del ángel' que no solo sabe crear personajes y mundos -Brétema vuelve a ser su lugar referencial-, sino que domina como pocos narradores actuales las claves de la concepción novelística (Gómez Yebra 2000).

Finalmente, en Casi perfecto (Mayoral 2007) encontramos un espacio narrativo urbano. Los personajes viven en Madrid, al igual que ocurría en otras novelas de Mayoral, pero en sus recuerdos la madre vuelve a su pequeña ciudad de infancia que no ha olvidado, Brétema, de donde salía para labrarse un futuro y adonde regresa continuamente con su pensamiento.

Brétema queda inmersa en la vida de cada personaje, que la hace suya y no puede alejarla nunca de sí, porque no se trata solamente de un paisaje, de un ambiente o de un vecindario, sino que forma parte de cada uno como un personaje más: es el lugar donde han nacido, han vivido y han soñado, han tenido que abandonar por el intento de buscar un futuro mejor, o el lugar al que han vuelto después de varias experiencias vividas por el mundo. Brétema estará siempre allí, esperándoles para que vuelvan a sentirse parte de ella, parte de un modo de ser, de un carácter y de una forma diferente de ver el mundo con otros ojos; miradas curiosas que buscan un por qué, que se preguntan por la vida de cada uno, por su pasado y por su futuro, e incluso por el motivo que ha llevado al señor Monterroso a andar solitario por las calles del corazón de Brétema una madrugada de otoño.

Ángel Basante, crítico en el Cultural de El Mundo, nos habla de su opinión sobre Brétema:

Su territorio literario es la ciudad imaginaria de Brétema, creando a partir de su Mondoñedo natal, bien reconocible por su clima de niebla (significado de 'brétema' en gallego) y lluvia persistentes, la 
omnipresencia de la catedral, cuyas campañas marcan el paso de las horas, y la asfixia vital y moral que se apodera de unas gentes condenadas a empujar la vida en un mundo cerrado en el que todos saben de todos y del que solo algunos logran escapar, sin que ello sea garantía de mayor felicidad con respecto a los que allí se quedan (Basante 2011).

Brétema, pues, atrapa, y aunque muchos intentan escapar de ella, siempre vuelven con sus recuerdos, quizás involuntarios; en cierto modo forman parte de su forma de ser, y eso no puede cambiarse. Quien ha nacido allí va a pertenecer siempre, y el que viene de fuera siempre será un extraño para los demás. En Brétema es todo o nada. La cuestión fundamental recae en si aceptas o no vivir bajo sus normas, bajo su mirada constante y los juicios diarios.

Dentro de este cuadro hay lugares concretos que cobran una importancia destacable. El reloj de la catedral, por ejemplo, se podría considerar el eje que mueve todo lo demás. Las campanas de la torre van marcando el paso de las horas, el fluir del tiempo, y marcan también hechos fundamentales, como la muerte inesperada de alguien una madrugada aparentemente normal. La farmacia será otro foco de interés, puesto que la vida de varios personajes estará vinculada a ella. En Deseos, la farmacia esconde el secreto de la supuesta violación de Dictino a Amalia, además de los planes de futuro de Blanca, sus amores y su decisión final.

Ahora bien, de todos los lugares que podríamos nombrar, el cementerio es sin duda uno de los más significativos. En Deseos cobra protagonismo desde la portada de la novela. Vinculada a este espacio tenemos a la protagonista, Constanza, que desnudará todas sus emociones y mundo interior entre las tumbas de sus amores pasados. Otros personajes, como Benilde, sentirán que el cementerio es el lugar idóneo para hablar con total sinceridad de lo que les inquieta o de alguna decisión importante, porque el cementerio siempre escucha y nunca juzga.

Si centramos nuestra atención en la última novela de Mayoral, Deseos, comprobaremos que cada personaje se relaciona con el otro gracias a Brétema, que funciona como hilo de unión de las distintas historias que se suceden desde la primera página a la última.

La creación de este microcosmos cerrado, en fin, ofrece a Marina Mayoral la posibilidad de adentrarnos en un mundo paralelo, imaginario, aunque uni- 
versal, donde cada lector puede encontrar una historia que se corresponda con algún aspecto de su vida real, adonde nuestra mente querría viajar y donde nuestra mirada busca descubrir los secretos que se esconden tras las ventanas. Por muy solo que puedas sentirte en determinados momentos, tienes la certeza de que, pese a las habladurías y los murmullos, Brétema estará siempre allí como un hombro al que arrimarte para contarle tus secretos, tus inquietudes y tus decisiones. Y tendrás la certeza de que cuentes lo que cuentes, la niebla lo va a barrer todo en unos pocos segundos y quedará para siempre encubierto.

\section{4 ¿Dónde Viven los Personajes?}

Franco Grande afirma:

O condado de Yoknapatampha, en Faulkner, o cidade de Santa María, en Onetti, Macondo, en García Márquez, ou Brétema, en Marina Mayoral, quedarán como referencias míticas da literatura deses autores. Na última deles, o ser Brétema segue acercándose e expandíndose, como acredita a súa última novela, por agora, baixo título Deseos [...] Compón uha sólida peza narrativa que arrequece a súa xa numerosa obra á por que enche de luz as brétemas da súa imaxinaria Brétema, anovándoa, expandíndoa, arrequentándoa, iluminándoa [...] (Franco Grande 2011).

¿Quién imagina un Dublín sin James Joyce, una Alejandría alejada de la pluma de Terenci Moix, Praga sin Kafka, el París de Cortázar, la isla de Robinson Crusoe, la Estambul de Pamuk, los pueblos por donde anduvo El Lazarillo de Tormes, la Castilla del Cid Campeador, Walt Whitman y su Washington o Juan Goytisolo sin su Marruecos?

[...] ciudades que se mimetizan con los que las vivimos, evocamos y visitamos más allá de los recorridos comunes, y de los consabidos lugares de interés cinco estrellas. No son entorno, se convierten en epidermis, en piel polisémica sensible a nuestros plurales estados de ánimo que encuentran su correlato en un atardecer encendido, en un aroma a sándalo, en una aurora tímida, en batiente ola o rosada piedra, en fin, en encuentro furtivo de aeropuerto o metro que se resiste a ser olvido y se transforma en mujer efímera e imposible. 
Las ciudades no son como ellas son, son también lo que va quedando en la remembranza, en la imaginación, en la visible invisibilidad de narradores o poetas, en el recuerdo propio que, ambivalentemente, es más generoso o más desdeñoso que la realidad misma (Viloria Vera 2008).

La relación de un escritor con su ámbito de creación es uno de los vínculos más estrechos que se puede establecer entre una obra de arte y la pluma que le da forma. Pensemos en cada uno de los novelistas que a lo largo del tiempo han ido creando espacios, ciudades, lugares donde recoger la esencia necesaria para pintar un cuadro único y novedoso, que capta la mirada del lector atento y consigue que vea ese universo propio con los ojos de sus personajes.

Hablamos de ciudades reales, pero también de contextos imaginarios. Qué más da si es realidad o ficción; al final nos hallamos en un mundo con una sensibilidad diferente y una luz única. La creación de cada marco en cada obra literaria supone entrar en otro cuarto, creado especialmente para ver la vida con unos ojos especiales, una mirada diferente que capta aquello que el autor quiere poner en relevancia. Del mismo modo que Virginia Woolf (1929) anunciaba que necesitaba una habitación propia donde escribir, estar en paz y poder crear sus novelas, cada autor necesitará de un cuarto propio donde situar las acciones y los personajes de las obras que surgen de su imaginación.

Estos espacios podrán ser ciudades reales, pueblos, ríos, playas, o también casas, callejuelas, cementerios o ambulatorios. Y aunque en muchas ocasiones se haga referencia a una ciudad o lugar real, hay que reconocer los matices subjetivos que hayen cada pisada y en cada abrir y cerrar de ventanas.

La mirada del autor deja impronta en todo aquello que recorren los ojos del lector. Su respiración está presente en cada coma, como también su estado de ánimo al amanecer un día sin sol, cubierto de niebla y con unas campanas tocando a muertos.

Podríamos encontrar diversos ejemplos de ciudades que han inspirado los creadores de historias. Pensemos en el Bogotá y Cali de Andrés Caicedo, el Buenos Aires de Jorge Luis Borges, Lima de Mario Vargas Llosa, Caracas de Salvador Garmendia, Nueva York y Nova Orleans de Truman Capote, el Londres eterno de Edgar Allan Poe, la Barcelona de Enrique Vila Matas, el París de Charles Baudelaire, la Lisboa de Fernando Pessoa, el San Petersburgo de Andréi Bely, la Nueva Orleans y Jefferson de William Faulkner, el México de Roberto Bolaño o la Venecia de Alfred de Musset. 
Además de referencias realistas, tenemos ciudades creadas que reúnen un cúmulo de otros espacios o surgidas por completo de la imaginación del autor. Ejemplos de ello serían las ciudades imaginarias de Juan Rulfo, de Juan Carlos Onetti, de Gabriel García Márquez, de Juan José Saer, etc.

Una cuestión que podemos plantearnos es por qué algunos narradores cambian el nombre a la ciudad en que centran su novela, mientras que otros lo respetan. Por ejemplo, por qué Galdós utiliza Madrid como tal y Clarín llama Vetusta a una ciudad que sin duda alguna es Oviedo. Si seguimos a Emilia Pardo Bazán, ella misma dejó claras las razones que la llevaron a cambiar el nombre a las ciudades de sus novelas:

Suelen preguntarme algunas personas por qué cambio el nombre a las localidades en que pasan mis novelas, y ya que va de confidencias novelesco-biográficas, diré las razones a que obedezco. Primera: precaver objeciones fundadas en cualquier inexactitud material que yo cometa, como si, por ejemplo, supongo que la feria de Cebre está a la entrada del pueblo cuando dista de él un cuarto de legua, o cosa por el estilo. Segunda: eximirme del realismo servil, que detesto tanto cuanto amo la verdad sentida que deducimos del conjunto y no de particularidades triviales. Tercera más libertad para crear el personaje; pues aunque la afirmación sorprenda, yo no he copiado jamás ninguno de los que en mis novelas figuran. Sobre que en ocasiones no es lícito ni delicado copiar, no es artístico nunca (Pardo Bazán 1886: 78-79).

En realidad, Pardo Bazán asume que el novelista no crea un espacio totalmente imaginario y nuevo, sino que recoge elementos de un paisaje conocido por hechos personales, culturales, etc. y lo transforma en el lugar de creación de nuevas historias.

Esta teoría es aplicable sobre todo a los personajes, que admiten más iniciativa del autor, porque en el hombre obran la libertad y la fatalidad, y en la naturaleza la fatalidad sola. El medio ambiente se impone, ya su imposición debemos el conocer la montaña santanderina en Pereda, las costumbres madrileñas en Galdós, la región asturiana en Armando Palacio y Leopoldo Alas, los pueblecillos catalanes y la segunda capital de España en Oller. Cada novelista, por natural impulso, acota su pedazo de tierra, sea provincial o natal o residencia acostumbrada (Pardo Bazán 1886: 80). 
Marina Mayoral nos indica que sus personajes nacen en un lugar llamado Brétema, de nombre gallego y cuyo significado es 'niebla'. Será el destino de algunos personajes o el lugar de partida de otros que van a vivir a Madrid o Nueva York, entre otros. En realidad, aunque muchos lo han apuntado de este modo, Brétema no es Mondoñedo, ciudad natal de la autora, sino que tiene rasgos de esa ciudad, como también los tiene de otras como Santiago de Compostela, Lugo o Foz.

Brétema, asume Mayoral, no es una ciudad, es un territorio; y solo existe en sus novelas. Es el lugar en que se encuentra todo lo necesario para hacer que las historias surjan y que sus personajes vivan. En ella se encuentran los paisajes más importantes de su vida:

Las montañas que rodean Mondoñedo, su catedral y el convento de las monjas enclaustradas; las calles de Santiago de Compostela y su parque de la Herradura y la universidad donde pasé tantos momentos de mis años de estudiante; el mar y las playas y los acantilados de Foz, casi en la línea con Asturias; las calles húmedas de niebla de Lugo... todo eso está en Brétema, es Brétema.

Los personajes de cada novela, sea cual sea su autor, están vinculados al entorno, viven en él y están muy influidos por él. En realidad, el paisaje lo vemos a través de los ojos del personaje, de modo que la realidad es mutable, cambia según sean unos ojos de cinco años o unos de sesenta. El paisaje, como afirma Mayoral, surge de la mirada del personaje; en otras ocasiones, incluso, es el propio personaje el que crea el paisaje. En un pasaje de la novela La única libertad (Mayoral 1982) se explica que a Etelvina le han dicho que desde lo alto de Cotomelos se puede ver el mar. Sin embargo, ella no lo ha visto nunca y desconfía de las palabras de Toño, el chico que hace de cartero y con el que inicia una relación especial. Pero un día lo dice Morais, y entonces ella crea el mar ante sus ojos:

Entonces hacía sol, un sol suave que destacaba los contornos y los colores sin herir la vista. Morais extendió la mano: Mira allí, entre las dos montañas de enfrente: es el mar. Me lo había dicho ya don Germán y también Toño, que se ofendió porque me eché a reír "¿el mar aquel triangulito gris entre las montañas?, ¿estás seguro?". Ahora la mano de Morais no dejaba lugar a dudas. Aquello era el mar: una línea recta entre la curva de dos montes, una manchita gris, distinta 
al gris azulado del cielo y al gris profundo de las montañas: el mar (Mayoral 1982: 258-262).

Las ciudades, los pueblos, los paisajes y los espacios que se nos dibujan en cada novela son lugares donde el lector tiene la posibilidad de dejarse llevar y soñar. Andar por las calles infinitas o pasar horas pensando en su cuarto propio, imaginando cómo sería una vida diferente, porque:

Como es bien sabido, al pasar a la ficción, la realidad deja de ser la realidad exterior, la que otros ven, para pasar a ver una realidad distinta: personal, interior, íntima. Por eso Flaubert pudo decir "Madame Bovary c'est moi". De igual forma yo tengo que decir: Brétema soy yo (Marina Mayoral).

\section{Bibliografía}

1. Anónimo, (1845). Vozes gallegas. Edición de J. Leitede Vasconcellos, RL vol. VII fasc. 3, pp. 198-229 (ms $7208 \mathrm{BN}$ ).

2. Basante, Á. (2011). Deseos. El Cultural. El Mundo, 17 de junio.

3. Carré Alvarellos, L. (1928-1931). Diccionario galego-castelán. A Coruña.

4. Cervantes TV. Entrevista a Marina Mayoral. Recuperado el 01/04/2013, de http://videos.cervantes.es/entrevista-a-marina-mayoral/

5. Franco Grande, X.L. (2011). Máis luz en Brétema. La Voz de Galicia (Suplemento cultural), 7 de mayo.

6. Gómez Yebra, A.A. (2000). Puntos de vista. Sur, 24 de junio.

7. Gullón, G. (1992). Introducción a la edición de Cándida, otra vez. Madrid: Castalia.

8. Leonés, Ó. (1982). Una familia lejana. Información, 20 de mayo.

9. Light Knight Productions. Deseos, la nueva novela de Marina Mayoral. Recuperado el 01/04/2013, de http://www.youtube.com/watch? $=\mathrm{tNdvOkwBcRY}$

10. Martín, S. (1995). Recóndita armonía, vivir para contarlo. Reseña, 260.

11. Mayoral, M. (1982). La única libertad. Madrid: Alfaguara.

12. Mayoral, M. (1992). Cándida, otra vez. Madrid: Castalia.

13. Mayoral, M. (1994). Recóndita armonía. Madrid: Alfaguara.

14. Mayoral, M. (1996). Dar la vida y el alma. Madrid: Alfaguara.

15. Mayoral, M. (2006). ¿Dónde viven mis personajes? In Valdivieso, J.H. \& Valdivieso, L.T. (eds.), Madrid en la literatura y las artes (pp. 71-75). Phoenix: Orbis Press. 
16. Mayoral, M. (2007). Casi perfecto. Madrid: Alfaguara.

17. Mayoral, M. (2009). ¿Quién mató a Inmaculada de Silva? Madrid: Alfaguara.

18. Mayoral, M (2011). Deseos. Madrid: Alfaguara.

19. Pardo Bazán, E. (1886). Los pazos de Ulloa. Madrid: Castalia, 1986.

20. Periodista digital. Entrevista a Marina Mayoral. Recuperado el 01/04/2013 http://www.youtube.com/watch?v=m2xVZSTeCQs

21. Porto Rey, F. (1900c). Diccionario gallego-castellano. Real Academia Galega, 2000 .

22. Reguera y Pardiñas, E. (1840-1858): Traducción de algunas voces, frases y locuciones gallegas, especialmente de agricultura, al castellano. Cadernos de Lingua, Real Academia Galega, 1995.

23. Rodríguez, F.J. (1863). Diccionario gallego-castellano. Edición de Antonio de la Iglesia González, A Coruña.

24. Rodríguez González, E. (1958-1961). Diccionario enciclopédico gallegocastellano. Vigo: Galaxia

25. RTVE a la carta. Deseos, Marina Mayoral. Un idioma sin fronteras Recuperado el 01/04/2013, de http://www.rtve.es/alacarta/audios/un-idioma-sinfronteras/idioma-sin-fronteras-deseos-marina-mayoral/

26. Suárez Lafuente, M. S. (2011). La recóndita armonía del universo Mayoral. La Nueva España, 28 de abril.

27. Viloria Vera, E. (2008). Ciudades y escritores. Caracas: Círculo de Escritores de Venezuela

28. Woolf, V. (1929). Una habitación propia (The room of one's own). Madrid: Alianza, 2012.

\section{Author's Biodata}

Anna Corts Curto es licenciada en filología española por la Universitat Rovira i Virgili. Ha sido becaria de docencia e investigación del Departament de Filologies Romàniques de la URV. Ha cursado un máster de Lingüística en la Universitat Pompeu Fabra. Sus intereses se centran en la utilización de herramientas formales para la descripción de fenómenos lingüísticos. Ha participado en varios congresos con trabajos en los que se defiende la necesidad del enfoque interdisciplinar para la solución de problemas relacionados con el procesamiento del lenguaje natural. 